\title{
Application of the dual attribute time-intensity (DATI) sensory method to the temporal measurement of bitterness and astringency in sorghum
}

\author{
Rosemary I. Kobue-Lekalake ${ }^{1,2}$, John R. N. Taylor ${ }^{1}$ and Henriëtte L. de Kock ${ }^{1,3}$ \\ ${ }^{1}$ Department of Food Science, University of Pretoria, Private Bag X20, Hatfield 0028, South Africa \\ ${ }^{2}$ Current address: Botswana College of Agriculture, Private Bag 0027, Gaborone, Botswana \\ ${ }^{3}$ Correspending author: Fax +27 12 4202839, E-mail: riette.dekock@up.ac.za
}

Running title: Bitterness and astringency in sorghum using DATI

\begin{abstract}
Bitterness and astringency are attributes generally cited as the cause of tannin sorghums being unpalatable. The objective here was to determine the effect of sorghums with varying tannin content on bitterness and astringency simultaneously using dual attribute time-intensity (DATI). A trained panel assessed bitterness and astringency of bran infusions of tannin and tannin-free sorghums. In both sorghum types, bitterness developed and reached maximum intensity faster $\left(T_{\max } 22.5 \mathrm{~s} ; \mathrm{p}<0.001\right)$ than astringency $(27.9 \mathrm{~s})$. The duration of the astringent sensation $\left(\mathrm{D}_{\text {tot }} 69.9\right.$ s) lasted longer than bitterness (66.3 s). Overall, the temporal parameters for bitterness distinguished infusions from tannin and tannin-free sorghums slightly more clearly than those for astringency. The research established that, for sorghum, bitterness and astringency are related. The DATI method also revealed that panellists' perceptions of the time course of bitterness and astringency differ.
\end{abstract}

Key Words: Dual attribute time-intensity; Bitterness; Astringency; Tannins; Sorghum 


\section{Introduction}

Sorghum grain is rich in phenolic compounds, the type and composition of which vary between sorghum genotype, but include phenolic acids, flavonoids and condensed tannins (proanthocyanidins or procyanidins) (reviewed by Dykes \& Rooney, 2006). There is great interest in sorghum types rich in phenolics because of their potential health-promoting properties. Consumption of tannin sorghum may help reduce obesity (reviewed by Awika \& Rooney, 2004). Importantly, flavonoid- and tannin-containing sorghums have high antioxidant activity (Awika et al., 2003). The high antioxidant activity of sorghum phenolics has been associated with protection against cardiovascular disease (reviewed by Awika \& Rooney, 2004). Certain sorghum phenolics, the 3-deoxyanthocyanins also appear to have specific anti-cancer effects (Shih et al., 2007).

However, phenolics impart both bitterness and astringency to fruits, vegetables, wine, beer and other foods (Drewnowski \& Gomez-Carneros, 2000).

Bitterness and astringency are sensory attributes generally cited as the cause of tannin sorghums (sorghums containing proanthocyanidins) being unpalatable (Asante, 1995; Awika \& Rooney, 2004; Yetneberk et al., 2005). This was confirmed in previous work to determine the consumer acceptability of food made from tannin sorghums (Kobue-Lekalake et al., 2009). The sorghum with the highest tannin content was rated significantly less acceptable than the other sorghums. In earlier work we carried out a quantitative descriptive analysis study to profile the sensory properties of tannin-free and tannin sorghums (Kobue-Lekalake et al., 2007). All the sorghum cultivars were to different degrees, perceived as both bitter and astringent. Sorghums with tannin levels exceeding 5.7\% catechin equivalents [CE] (dry basis) were most bitter and most astringent, 
whilst the sorghums with no detectable tannins were least bitter and least astringent. Surprisingly NS 5511, with a tannin content level of 1.8\% CE was perceived as similar to PAN 8564 (with no detectable tannins) in bitterness and astringency as well as other sensory attributes. More importantly, it was found that all the sorghum cultivars, both those that contained condensed tannins and those which only contained other types of phenolics, were, to different degrees, perceived as both bitter and astringent.

Chandreshakar et al. (2000) reported that transduction of bitter taste is mediated through G protein-coupled taste receptors (GPCR) and specific T2R taste receptors. Although not accepted by all researchers (as is evident from the review by Bajec and Pickering, 2008), there is evidence that astringency is an oral tactile sensation signalled by trigeminal nerves (Vidal et al., 2003). As such astringency is defined as a binding reaction relating to the ability of astringent materials to bind and precipitate proteins (Haslam \& Lilley, 1988; Lee \& Lawless, 1991) leading to drying, puckering and roughing sensations in the mouth. Considering that tannins elicit both bitter and astringent responses and taking into account the mechanisms of reception described, it may be assumed that tannins in sorghum would evoke both a bitter and astringent response until salivary proteins bind the available tannins to such an extent that the tactile astringent sensation would predominate the bitter taste sensation. Noble (1990) reported that the perception of astringency has a slower onset when compared to bitterness, but both attributes are characterized by a long persistence. Leach (1984), also found that bitterness and astringency are characterized by a persistency and suggested that these properties cannot be estimated fully by single scalar intensity procedures. The scalar or unipoint estimates of intensity are inadequate when the sensory properties of samples vary differentially over time (Noble, 1995). Thus, to fully characterize the differences in bitter and astringent properties of sorghum requires analysis of the time-course of 
perceived intensity. The time-intensity sensory evaluation method is useful in continuously capturing, in great detail, the nuances of flavour growth, decay and disappearance in the mouth (Lawless \& Heymann, 1998; Bloom et al., 1994). Time-intensity sensory evaluation has mostly been used to measure single attributes. However it is gaining more popularity for measuring more than one attribute. The dual attribute time-intensity (DATI) method assesses two sensory

attributes simultaneously (Duizer et al., 1997). More recently, the temporal dominance of sensations (TDS) method has been developed and it assesses repeatedly, until the sensory perception ends, which sensation is dominant and its intensity (Labbe et al., 2009). To our knowledge, no study has reported simultaneous dual temporal measurement of the taste, bitter and the tactile sensation, astringency.

Since the conventional descriptive sensory method used in our previous study could only measure unipoint scalar intensities of bitterness and astringency in different sorghum types, we applied the DATI method to measure the development, evolution, persistence and intensity of bitterness and astringency simultaneously.

\section{Materials and methods}

\section{Sorghum grain}

Six sorghum cultivars containing different levels of total phenols and condensed tannins were used as described by Kobue-Lekalake et al., (2007). Three were tannin-free sorghums (PAN 8564, Segaolane and Phofu) with total phenol contents of $0.37,0.17$ and $0.22 \%$ tannic acid equivalents [TAE] db, respectively. PAN 8564 is a South African hybrid grown in 1999, while Segaolane and Phofu are open pollinating varieties grown in Botswana in 2004. The other three were tannin 
sorghums (PAN 3860, Ex Nola 97 GH and NS 5511) with total phenol contents of 1.75, 1.71 and $1.06 \% \mathrm{TAE}$, respectively; and condensed tannin contents of $8.21,5.70$ and $1.78 \% \mathrm{CE} \mathrm{db}$, respectively (Kobue-Lekalake et al., 2007). PAN 3860, Ex Nola 97 GH and NS 5511 are type III hybrids grown in South Africa in 2004, 1997 and 2004 respectively. Total phenol content was determined using the Folin-Ciocalteu method of Waterman and Mole (1994), and condensed tannins determined using the modified Vanillin- $\mathrm{HCl}$ method as described by Price et al. (1978). The tannin sorghums had a red pericarp. One tannin-free sorghum had a red pericarp (PAN 8564) and the other tannin-free sorghums had white pericarp (Kobue-Lekalake et al., 2007).

\section{Sorghum bran infusions}

Sorghum bran was used as the source of tannins and non-tannin polyphenols, as these compounds are concentrated in the pericarp and testa layers of the sorghum grain (reviewed by Awika and Rooney, 2004). Bran hot water infusions were used to avoid any possible delay in contact between the phenolics and the panellists' "taste" receptors, resulting from interference by the bran matrix in which the phenolics are located. Brans isolated from the sorghum grains were used to prepare the infusions as described previously (Kobue-Lekalake et al., 2007). Boiling $\left(96^{\circ} \mathrm{C}\right)$ deionised water (300 ml) was added to the sorghum bran $(5 \mathrm{~g})$ in a glass beaker and covered with aluminium foil, and then boiled on a hot plate for $20 \mathrm{~min}$. The sorghum bran mixture was centrifuged at $3880 \mathrm{~g}$ for 5 min at $20^{\circ} \mathrm{C}$. The supernatant (bran infusion) was recovered and kept at $4{ }^{\circ} \mathrm{C}$ for not more than $12 \mathrm{~h}$ before use. The residue was discarded. The bran infusions were brought to room temperature $\left(c a .18^{\circ} \mathrm{C}\right)$ before being served to the panellists. 


\section{Descriptive sensory panel selection and training}

Twelve panellists (six women and six men) aged 19-39 years, all screened to be 6-n-propyl-2thiouracil (PROP) sensitive (Tepper, 1999), participated in the study. These panellists were previously extensively trained when they participated in a study to describe the sensory attributes of cooked sorghum rice (Kobue-Lekalake et al., 2007). The descriptive sensory panel was further trained for $10 \mathrm{~h}$ to familiarize them with the Compusense DATI method (Compusense ${ }^{\circledR}$ Five release 4.6 [1986-2003] Guelph, Ontario Canada) and SATI and DATI sensory evaluation methodology as described by Peyvieux \& Dijksterhuis (2001). Initially, the training was carried out measuring a single attribute (bitterness) on a structured horizontal line. The line scale had 10 markings from $0=$ none (at the start position) to $100=$ extreme (at the end of the line). As the intensity of the bitterness increased, the panellist moved the 'marker' to the right, and when the intensity of the bitterness decreased he/she moved the 'marker' to the left. The speed with which they moved the 'marker' to the right or left was determined by how rapidly the intensity of the attribute developed and increased or how rapidly it decreased. The panellists were also trained to differentiate between bitterness and astringency using standards (dissolved in deionised water) and concentrations used by Kallithraka et al. (1997a) bitterness (1.0 g/l caffeine; food grade), and astringency (1.5 g/l tannic acid [gallotannin]; 48811 Fluka/Sigma-Aldrich, Atlasville, South Africa). Alum (potassium aluminium sulphate Fluka/Sigma-Aldrich, Atlasville, South Africa) was also used to familiarize the panellists with the astringency sensation using the concentration $(0.5$ g/l) recommended in ISO 8586 (International Organization for Standardization, 1993).

Training to measure dual attributes simultaneously (bitterness and astringency) was introduced only after the panellists were proficient in measuring the sensations as single attributes. The panellists were trained to measure the intensity of bitterness on a structured vertical line and 
the intensity of astringency on a structured horizontal line simultaneously, by moving a computer mouse diagonally on a mouse pad; to the right as the attributes developed and increased, and to the left as the attributes decreased. Moving the mouse diagonally moved the 'marker' along both lines (vertical and horizontal) simultaneously. During training, time intervals of 2, 3, 4 and 5 min were used in between samples to determine the optimal time interval required to minimize carry over effects. The panellists agreed on a 4 min time interval in between samples to minimize carry over effects. This time interval was also used by Kallithraka et al. (1997b) in their study using the timeintensity methodology to assess the effects of $\mathrm{pH}$ on the astringency of model solutions and wines.

\section{Sample presentation and assessment}

Sorghum bran infusions of the six sorghum cultivars were assessed using the Compusense DATI method four times per product, with two sessions per day. Three cultivars assessed in the first session and the other three assessed after two hours in order to minimize fatigue and astringency build-up. To balance out any order effect, sample presentation order was randomized over the panellists for all the four replications. Random three digit numbers were used to code the samples.

Panellists sat in individual booths and evaluated the samples under white light. Samples (15 ml) were served in size 8 glass tubes covered with lids. Panellists were instructed to place the whole sample in the mouth and swirl it around without swallowing it, and immediately start evaluating the intensity of the bitterness and astringency, simultaneously. After $15 \mathrm{~s}$ the panellists expectorated the sample. The panellists measured the intensity of the two attributes, bitterness and astringency, simultaneously and continuously from the time they placed the sample in their mouth to the end of the assessment period of $90 \mathrm{~s}$. The DATI software was programmed to collect responses every $0.5 \mathrm{~s}$ for the total duration of $90 \mathrm{~s}$. A four minute interval was enforced between 
samples to minimize carry over effects from one sample to another. The panellists were given pieces of raw carrots and deionised water to cleanse their mouths thoroughly before tasting and in between samples.

\section{Statistical analysis}

Four parameters were extracted from the time-intensity curves: $\mathrm{T}_{\max }$ (time to reach maximum intensity), $\mathrm{I}_{\max }$ (maximum intensity), $\mathrm{D}_{\text {tot }}$ (total duration of sensation) and AUC (area under curve). The generalized linear model (PROC GLM) was used to analyze the effects of session, panellist, replicate, sample order and cultivar as fixed effects and designated interaction effects on $T_{\max }, I_{\max }$, $\mathrm{D}_{\text {tot }}$ and AUC data for bitterness and astringency using SAS ${ }^{\circledR}$ version 8.2 (SAS Institute Cary, NC). This approach was selected to account for possible bitterness and/or astringency build up or training effects between sessions and over replicates. An alternative would be to treat some or all of the independent variables as random effects following the guidelines of e.g. Næs \& Langsrud (1998).

GLM model:

$$
y=\mu+\alpha_{i}+\beta_{j}+\gamma_{k}+\delta_{l}+\varepsilon_{m}+(\alpha \beta) i_{j}+(\beta \gamma)_{j k}+(\beta \delta)_{j l}+(\beta \varepsilon)_{j m}+\xi
$$

Where:

$\mu$ - mean; $\alpha_{i}$ - session; $\beta_{j}$ - panellist; $\gamma_{k}$ - replicate; $\delta_{l}$ - sample order; $\varepsilon_{m}$ - cultivar; $\xi$ - error.

Fishers' least significant difference test $(\mathrm{p}<0.05)$ was used to compare the means. Linear relationships (Pearson's correlation coefficient) between the time-intensity parameters ( $T_{\max }, I_{\max }$, 
$\mathrm{D}_{\text {tot }}$ and AUC) were calculated. A comparison of the time-intensity parameters for bitterness and astringency was performed using ANOVA.

\section{Results and discussion}

The results are presented and discussed in three parts, cultivars with varying tannin content, panellist and design effects on measurement of bitterness and astringency. The GLM model used was appropriate because it explained $79-83 \%$ of the variance in all the parameters for bitterness (Table 1) and explained $69-84 \%$ of the variance in the parameters for astringency (Table 2).

\section{Effect of sorghum cultivars with varying tannin content}

There were highly significant cultivar effects $(\mathrm{p}<0.001)$ for all the time-intensity parameters ( $T_{\max }, I_{\max }, D_{\text {tot }}$ and AUC) for bitterness (Table 1) and astringency (Table 2). The most bitter $\left(I_{\max }\right)$ sorghum infusions were from tannin sorghums, PAN 3860 and Ex Nola 97 GH with tannin contents of 8.2 and $5.7 \% \mathrm{CE}$, respectively (Table 3). The bitterness of the infusion from NS 5511, a type III sorghum with a relatively low tannin sorghum $(1.8 \% \mathrm{CE})$, was not significantly different from that of the tannin-free sorghums. With the exception of NS 5511, it took approximately 7-10 s longer $\left(T_{\max }\right)$ to reach maximum bitterness intensity for tannin-containing sorghums (PAN 3860 and Ex Nola $97 \mathrm{GH})$ than the tannin-free sorghums. The duration $\left(\mathrm{D}_{\mathrm{tot}}\right)$ of bitterness for the most bitter sorghums (PAN 3860 and Ex Nola $97 \mathrm{GH}$ ) was generally 9-12 s longer than that of the less bitter sorghums. The more bitter the infusion, the longer $\left(T_{\max }\right)$ it took to reach maximum intensity $\left(I_{\max }\right)$ and the longer the $\mathrm{D}_{\text {tot. }}$. The more bitter the infusion, the larger the AUC as reflected by the highly significant $(\mathrm{r}=0.88, \mathrm{p}<0.001)$ positive correlation. 
As observed for bitterness, the most astringent infusion (highest $\mathrm{I}_{\max }$ ) was from PAN 3860 (Table 3), which had the highest tannin content (8.2\% CE). Although the infusion of Ex Nola 97 GH $(5.7 \% \mathrm{CE})$ was significantly more bitter than that of PAN 8564, which had no detectable tannins, the astringency of their infusions were not significantly different (Table 3). The finding here agrees with the quantitative descriptive analysis (Kobue-Lekalake et al., 2007). Thus, it appears that bitterness and astringency are generally, but not always, the same in level of strength in individual sorghum cultivars. The bitterness and astringency of PAN 8564 (with no detectable tannins) was perceived similar to that of tannin sorghum NS $5511(1.8 \% \mathrm{CE})$ and its astringency was not significantly different from that of Ex Nola $97 \mathrm{GH}(5.7 \% \mathrm{CE})$. The astringency $\left(\mathrm{I}_{\max }\right)$ of the infusion from NS 5511 was not significantly different from all the tannin-free sorghums. Since PAN 8564 does not contain condensed tannins (proanthocyanidins), the anthocyanins in the red pericarp of this sorghum may be the cause of it being perceived similar to NS 5511 bitterness and astringency and similar in astringency to Ex Nola $97 \mathrm{GH}$. Additionally, when the bran of tannin sorghums was boiled in deionised water to make infusions, some of the condensed tannins would have bound to the proteins in the germ. Some protein is located in the germ of the sorghum caryopsis (Rooney \& Miller, 1982; Taylor \& Schüssler, 1986). The formation of condensedtannin-protein complexes led to a reduction in the quantity of condensed tannins available to bind the salivary proteins during tasting, thus explaining the apparent 'reduction' in astringency of Ex Nola $97 \mathrm{GH}$ and NS 5511 that resulted in their infusions being perceived as similar to PAN 8564.

The $\mathrm{T}_{\max }$ of the least astringent sorghum infusion (Phofu) was shorter than that of the most astringent infusion (PAN 3860) (Table 3). Likewise, the $\mathrm{D}_{\text {tot }}$ of the least astringent infusion (Phofu) was shorter than that of the most astringent infusion (PAN 3860). The $\mathrm{T}_{\max }$ was generally longer (4-8 s) for the tannin sorghums (PAN 3860, Ex Nola 97 GH and NS 5511) than the tannin- 
free sorghums (PAN 8564, Segaolane and Phofu). With the exception of NS 5511, the total duration $\left(\mathrm{D}_{\text {tot }}\right)$ of astringency of the tannin sorghums (PAN 3860 and Ex Nola $\left.97 \mathrm{GH}\right)$ lasted significantly longer (7-12 s) than that of the tannin-free sorghums.

Bitterness took a significantly shorter time to reach maximum intensity than astringency (Table 3). The mean $T_{\max }$ for bitterness was $22.5 \mathrm{~s}$, whereas for astringency the mean $\mathrm{T}_{\max }$ was $27.9 \mathrm{~s}$. This might be due to the fact that bitterness is a basic taste (Lawless and Heymann, 1998) that can be detected at very low concentrations (Glendinning, 1994). Bitter taste perception is thought to have evolved to prevent ingestion of potential poisons (Glendinning, 1994; Rodgers et al., 2005). Unlike bitterness, astringency is a physical sensation (Breslin et al., 1993). When tannins bind proteins present in the saliva, the conformational changes result in the salivary proteins losing their lubricating power, resulting in a dry and puckery feeling in the mouth (Joslyn \& Goldstein, 1964). The tactile sensations caused by increased friction (decrease in salivary lubrication) between oral membranes are the primary basis of astringent sensations (Breslin et al., 1993). The finding here, agrees with the observation that astringency is often the last sensation detected (Kallithraka et al., 2001).

The mean duration of the astringent sensation was significantly $(\mathrm{p}<0.05)$ longer by $3.6 \mathrm{~s}$ than the duration of bitterness (Table 3). The findings on the sorghum bran infusions agree with the observations of Leach (1984) who determined the bitterness and astringency of gallic acid, catechin, grape seed tannin and tannic acid using a single attribute time-intensity sensory method, and reported that the duration $\left(D_{\text {tot }}\right)$ of astringency was generally longer by $10-15 \mathrm{~s}$ than that of bitterness. A significantly shorter time $\left(\mathrm{T}_{\max }\right)$ was required to reach $\mathrm{I}_{\max }$ for less astringent compounds like gallic acid and catechin, than for the more astringent compounds, tannic acid and grape seed tannin. Furthermore, duration $\left(\mathrm{D}_{\mathrm{tot}}\right)$ of bitterness and astringency increased with 
increasing intensity $\left(\mathrm{I}_{\max }\right)$ of bitterness and astringency. King \& Duineveld (1999) studied the bitterness in beer during ageing and observed a significant positive correlation between $\mathrm{I}_{\max }$ and AUC $(r=0.95, p<0.05)$.

\section{Panellist effect}

There was a highly significant $(\mathrm{p}<0.001)$ panellist effect for all the time-intensity parameters for both bitterness (Table 1) and astringency (Table 2). Some panellists (Table 4) found the infusions more astringent than bitter (panellists 3 and 5), whilst others found them more bitter than astringent (2 and 11). Some panellists (4 and 11) routinely used the upper end of the scale, whilst others (3,7 and 9) used the lower end. Panellists 6, 9 and 11 experienced the bitterness and astringency of the infusions a lot longer $\left(D_{\text {tot }}>80 \mathrm{~s}\right)$ whereas for panellists 1 and 12 it only lasted between 50 and $60 \mathrm{~s}$. The astringency and bitterness sensations developed very slowly for Panellists 1 and $11\left(\mathrm{~T}_{\max }\right)$.

According to Tomic et al. (2007), differences in time-intensity data among panellists may be due to them using the time-intensity scale differently, the panellists experiencing sensory attributes differently (e.g. day to day physiological and psychological biases), and/or random error. This phenomenon has been reported by many other researchers (Leach and Noble, 1986; Noble et al., 1991; Kallithraka et al., 2001; François et al., 2006)

This study did not determine the panellist's salivary flow rates, or the physical-chemical characteristics of the saliva of the panellists. However, it is probable that differences in astringency perceptions could be related to different individual salivary flow rates, as was found by Kallithraka et al. (2001), Fischer et al. (1994) and Ishikawa and Noble (1995) with wine, François et al. (2006) with beer. Subjects with a high salivary flow rate perceived astringency at a lower level than those with a low flow rate. The physical-chemical characteristics of saliva are not 
constant and vary within a person over time and between individuals. Dinnella et al. (2009) investigating the relations between individual physiological differences in saliva and sensitivity to (phenolic) astringent stimuli, concluded that subjects capable of maintaining constant salivary characteristics were less sensitive to astringent stimuli compared to subjects in whom the same stimuli induced significant saliva modifications.

Another consideration could be the complexity of paying attention to two different attributes, and simultaneously tracking their changes (Dijksterhuis and Piggott, 2001). Notwithstanding the fact that measuring two different attributes simultaneously is complex, this method revealed differences in the rates of bitterness and astringency development and persistence.

There were significant interaction effects: panellist by session, panellist by replicate, and panellist by sample order for astringency (Table 1); and panellist by session, panellist by replicate and panellist by cultivar for bitterness (Table 2).

There was a significant panellist by cultivar interaction effect for $\mathrm{T}_{\max }, \mathrm{I}_{\max }$ and AUC for bitterness (Table 1). All the panellists were bitter sensitive. However, variation in bitterness sensitivity is well documented (Bartoshuk et al., 1994; Miller and Reedy, 1990; Tepper, 1998; Tepper, 1999). There was no significant panellist by cultivar interaction effect for astringency, indicating that the individual panellists agreed on the relative difference in astringency of the sorghum cultivars (Table 2). The interindividual differences presented here, may possibly present a limitation when generalising on the differences in bitterness and astringency among the sorghum cultivars. 


\section{Design and other interaction effects}

Variations $(\mathrm{p}<0.001)$ noted between sessions were for $\mathrm{I}_{\max }$ and AUC for astringency (Table 2). Overall, the panel rated the $I_{\max }$ astringency of samples on a day higher during the second session than the first (data not shown). However, there was a significant panellist by session interaction effect for astringency $\mathrm{I}_{\max }$ and $\mathrm{D}_{\text {tot }}(\mathrm{p}<0.05, \mathrm{p}<0.01$, respectively) (Table 2 ) and a significant $(\mathrm{p}<0.05)$ panellist by session interaction effect for bitterness $\mathrm{I}_{\max }$ (Table 1). For astringency, some of the panellists rated $\mathrm{I}_{\max }$ of samples in the second session much higher than those in the first session and total duration $\left(\mathrm{D}_{\text {tot }}\right)$ of some of the panellists was rated longer in session 1 than session 2, whilst for others it was the reverse (data not shown). A similar observation was noted for bitterness $I_{\max }$ (data not shown) and attributed to random variation.

There were also significant $(\mathrm{p} \leq 0.05)$ replicate variations for bitterness for $\mathrm{T}_{\max }, \mathrm{I}_{\max }$ and AUC (Table 1). For astringency, the only significant $(\mathrm{p}<0.05)$ replicate effect was for $\mathrm{T}_{\max }$ (Table 2). Again, however, the main effect differences were further explained by interactions with panellist effects. A significant $(\mathrm{p}<0.05)$ panellist by replicate interaction effect for bitterness AUC (Table 1), and significant ( $\mathrm{p}<0.05,0.01,0.01$, respectively) panellist by replicate interaction effects for astringency $T_{\max }, I_{\max }$ and AUC (Table 2) were found. Panellists rated the samples differently on different days (replications) (data not shown) but no clear trend was observed implying that the observed differences were due to random variation.

For both bitterness and astringency, there was no significant main effect differences observed related for the order in which the samples were evaluated (Tables 1 and 2, respectively). No clear trend was observed (data not shown) for the significant panellist by sample order interaction effect for astringency $\mathrm{I}_{\max }(\mathrm{p}<0.05)$ and AUC $(\mathrm{p}<0.01)$ (Table 2). 


\section{Conclusions}

The DATI sensory method allowed for simultaneously temporal measurement of bitterness and astringency of sorghums varying in total phenol and tannin content. For both tannin and tanninfree sorghums, bitterness developed and reached maximum intensity significantly faster than astringency. Overall, the temporal parameters for bitterness distinguished infusions from tannin and tannin-free sorghums more clearly than those for astringency. However, the total duration of the astringent sensation lasted significantly longer than bitterness. Consistent with our descriptive sensory study (Kobue-Lekalake et al., 2007), the results of this study show that tannin sorghums are more bitter and astringent than tannin-free sorghums and also that the more bitter the sorghum the more astringent it is. The DATI method also revealed that panellists' perceptions of the time course of bitterness and astringency differ. Some panellists seem more sensitive to or focused on bitterness than astringency whilst the opposite is true for others. This may explain why some persons claim that tannin sorghums are bitter while others describe them as astringent. In sorghum

these two properties are closely associated. In future work it would be useful to conduct a study to identify and quantify the monomers, dimers and oligomers of polyphenols in sorghum and their effect on bitterness and astringency. In future work it will be useful to study time intensity assessment of astringency and bitterness between cultivars in actual sorghum food and beverage products and compare the results with these present findings.

\section{Acknowledgements}

This material is based on work supported by the South African National Research Foundation (NRF GUN number 2073269). The authors wish to thank Dr. M. van der Linde and Dr. F.H.J. 
Kanfer of the Department of Statistics of the University of Pretoria for their assistance with some of the statistical analysis of the research data.

\section{References}

Asante, S.A. (1995). Sorghum quality and utilization. African Crop Science, Journal, 3, 231-240.

Awika, J.M. \& Rooney, L.W. (2004). Sorghum phytochemicals and their potential impact on human health. Phytochemistry, 65, 1199-1221.

Awika, J.M., Rooney, L.W., Wu, X., Prior, R. \& Cisneros-Zevallos, L., (2003). Screening methods to measure antioxidant activity of sorghum (Sorghum bicolor) and sorghum products. Journal of Agricultural and Food Chemistry, 57, 6657-6662.

Bartoshuk, L.M., Duffy, V.B. \& Miller, I.J. (1994). PTC/PROP tasting: anatomy, psychophysics and sex effects. Physiology and Behavior, 56, 1165-1171.

Bajec, M. R. \& Pickering, G. J. 2008. Astringency: Mechanisms and Perception. Critical Reviews in Food Science and Nutrition, 48:1-18.

Bloom, K., Duizer, L.M. \& Findlay, C.J. (1994). An objective numerical method of assessing the reliability of time intensity panellists. Journal of Sensory Studies, 10, 285-294. 
Breslin, P.A.S., Gilmore, M.M., Beauchamp, G.K. \& Green, B.G. (1993). Psychophysical evidence that oral astringency is a tactile sensation. Chemical Senses, 18, 405-417.

Chandrashekar, J., Mueller, K.L., Hoon, M. A., Adler, E., Feng, L., Guo, W., Zuker, C.S. \&. Ryba, N. J. P. (2000). T2Rs function as bitter taste receptors. Cell, 100, 703-711.

Dijksterhuis, G.B. \& Piggott, J.R. (2001). Dynamic methods of sensory analysis. Trends in Food Science and Technology, 11, 284-290.

Dinnella, C., Recchia, A., Fia, G., Bertuccioli, M. \& Monteleone, E. (2009). Saliva characteristics and individual sensitivity to phenolic astringent stimuli. Chemical Senses, 34, 295-304.

Drewnowski, A. \& Gomez-Carneros, C. (2000). Bitter taste, phytonutrients, and the consumer: a review. American Journal of Clinical Nutrition, 72, 1424-1435.

Duizer, L.M., Bloom, K. \& Findlay, C.J. (1997). Dual-attribute time intensity sensory evaluation: a new method for temporal measurement of sensory perceptions. Food Quality and Preference, 8, 261-269.

Dykes, L. \& Rooney, L.W. (2006). Sorghum and millet phenols and antioxidants. Journal of Cereal Science 44, 235-251. 
Fischer, U., Boulton, R.B. \& Noble, A.C. (1994). Physiological factors contributing to the variability of sensory assessments: relationship between salivary flow rate and temporal perception of gustatory stimuli. Food Quality and Preference, 5, 55-64.

François, N., Guyot-Declerck, C., Hug, B., Callemien, D., Govaerts, B. \& Collin, S. (2006). Beer astringency assessed by time intensity and quantitative descriptive analysis: Influence of $\mathrm{pH}$ and accelerated aging. Food Quality and Preference, 17, 445-452.

Glendinning, J.L. (1994). Is the bitter rejection response always adaptive? Physiology and Behavior, 56, 1217-1227.

Haslam, E. \& Lilley, T.H. (1988). Natural astringency in food-stuffs - a molecular approach. $C R C$ Critical Reviews in Food Science and Nutrition, 27, 1-40.

International Organization for Standardization (ISO) (1993). Sensory analysis - guidelines for selection, training and monitoring of assessors - Part 1: Selected assessors (ISO 8586). Geneva: Switzerland: ISO.

Ishikawa, T. \& Noble, A.C. (1995). Temporal perception of astringency and sweetness in red wine. Food Quality and Preference, 6, 27-33.

Joslyn, M.A. \& Goldstein, J.L. (1964). Astringency in fruits and fruit products in relation to phenolic content. Advances in Food Research, 13, 179-217. 
Kallithraka, S., Bakker, J. \& Clifford, M.N. (1997a). Effect of pH on astringency in model solutions and wines. Journal of Agriculture and Food Chemistry, 45, 2211-2216.

Kallithraka, S., Bakker, J. \& Clifford, M.N. (1997b). Evaluation of bitterness and astringency of $(+)$ catechin and (-) epicatechin in red wine and in model solutions. Journal of Sensory Studies, 12, 25-37.

Kallithraka, S., Bakker, J., Clifford, M.N. \& Vallis, L. (2001). Correlations between saliva protein composition and some T-I parameters of astringency. Food Quality and Preference, 12, 145-152.

King, B.M. \& Duineveld, CAA. (1999). Changes in bitterness as beer ages naturally. Food Quality and Preference, 10, 315-324.

Kobue-Lekalake, R.I., Taylor, J.R.N. \& De Kock, H.L. (2007). Effects of phenolics in sorghum grain on its bitterness, astringency and other sensory properties. Journal of the Science of Food and Agriculture, 87, 1940-1948.

Kobue-Lekalake, R.I., Taylor, J.R.N. \& De Kock, H.L. (2009). Influence of PROP taster status on the consumer acceptability of food made from tannin sorghums. Journal of the Science of Food and Agriculture, 89, 1809-1814. 
Labbe, D., Schlich, P., Pineau, N., Gilbert, F. \& Martin, N. (2009). Temporal dominance of sensations and sensory profiling: A comparative study. Food Quality and Preference, 20, 216221.

Lawless, H.T. \& Heymann, H. (1998). Sensory Evaluation of Food: Principles and Practices. Gaithersburg (MD): Aspen Publishers.

Leach, E.J. (1984). Evaluation of astringency and bitterness by scalar and time intensity procedures. PhD Thesis. University of California, Davis.

Leach, E.J. \& Noble, A.C. (1986). Comparison of bitterness of caffeine and quinine by a time intensity procedure. Chemical Senses, 11, 339-345.

Lee, C.B. \& Lawless, H.T. (1991). Time-course of astringency sensations. Chemical Senses, 16, $225-238$.

Miller, I.J. \& Reedy, F.E. (1990). Variations in human taste bud density and taste intensity perception. Physiology and Behavior, 47, 1213-1219.

Næs T. \& Langsrud, Ø. (1998). Fixed or random assessors in sensory profiling. Food Quality and Preference. 9 (3), 145-152.

Noble, A.C. (1990). Bitterness and astringency in wine. In: Bitterness in Foods and Beverages. Developments in Food Science (edited by R. L. Roussef). Pp. 145-158. Amsterdam: Elsevier. 
Noble, A.C. (1995). Application of time intensity procedures for evaluation of taste and mouthfeel. American Journal Enology and Viticulture, 46, 128-133.

Noble, A.C., Matysiak, N.L. \& Bonnans, S. (1991). Factors affecting time intensity parameters of sweetness. Food Technology, 45, 121-126.

Peyvieux, C. \& Dijksterhuis, G. (2001). Training a sensory panel for TI: a case study. Food Quality and Preference, 12, 19-28.

Price, M.L., Van Scoyoc, S. \& Butler, L.G., (1978). A critical evaluation of the vanillin reaction as an assay for tannin in sorghum grain. Journal of Agricultural and Food Chemistry, 26, 12141218.

Rodgers, S., Busch, J., Peters, H. \& Christ-Hazelhof, E. (2005). Building a tree of knowledge: analysis of bitter molecules. Chemical Senses, 30, 547-557.

Rooney, L.W. \& Miller, F.R. (1982). Variation in the structure and kernel characteristics of sorghum. In: Proceedings of the International Symposium on Sorghum Grain Quality (edited by L. W. Rooney \& D. S. Murty). Pp. 143-162. Patancheru, India: ICRISAT.

Shih, C.-H., Sui, S.-O., Ng, R, Wong, E., Chiu, L.C.M., Chu, I.K. \& Lo, C. (2007). Quantitative analysis of anticancer 3-deoxyanthocyanidins in infected sorghum seedlings. Journal of Agricultural and Food Chemistry 55, 254-259. 
Taylor, J.R.N. \& Schüssler, L. (1986). The protein compositions of different anatomical parts of sorghum grain. Journal of Cereal Science, 4, 361-369.

Tepper, B.J. (1998). Genetics of Perception '98 6-n-propylthiouracil: a genetic marker for taste with implications for food preference and dietary habits. American Journal of Human Genetics, 63, $1271-1276$.

Tepper, B.J. (1999). Does genetic taste sensitivity to PROP influence food preferences and body weight. Appetite, 32, 422.

Tomic, O., Nilsen, A., Martens, M. \& Nǽs, T. (2007). Visualization of sensory profiling data for performance monitoring. LWT-Food Science and Technology, 40, 262-269.

Vidal, S., Francis, L., Guyot, S., Marnet, N., Kwiatkowski, M., Gawel, R., Cheynier, V. \& Waters, E.J. (2003). The mouth-feel properties of grape and apples proanthocyanidins in a wine-like medium. Journal of the Science of Food and Agriculture, 83, 564-573.

Waterman, P.G. \& Mole, S. (1994). Analysis of Phenolic Plant Metabolites Extraction and Chemical Quantification. Pp. 66-10. Oxford, UK. Blackwell Scientific Publications.

Yetneberk, S., Rooney, L.W. \& Taylor, J.R.N. (2005). Improving the quality of sorghum injera by decortication and compositing with tef. Journal of the Science of Food and Agriculture, 85, 12521258. 
Table 1 Degrees of freedom (df), R-squared and F-values from analysis of variance of parameters extracted from time intensity curves for bitterness in sorghum bran infusions

\begin{tabular}{|c|c|c|c|c|c|}
\hline $\begin{array}{l}\text { Source of } \\
\text { variation }\end{array}$ & df & $\begin{array}{l}\text { Time to Max } \\
\left(\mathbf{T}_{\max }\right) \\
\mathrm{R}^{2}-0.81\end{array}$ & $\begin{array}{l}\text { Intensity at Max } \\
\left(I_{\max }\right) \\
R^{2}-0.84\end{array}$ & $\begin{array}{l}\text { Total Duration } \\
\left(D_{\text {tot }}\right) \\
R^{2}-0.69\end{array}$ & $\begin{array}{l}\text { Area Under Curve } \\
\text { (AUC) } \\
\mathrm{R}^{2}-0.83\end{array}$ \\
\hline Main effects & & & & & \\
\hline Cultivar & 5 & $11.54 * * *$ & $38.32 * * *$ & $6.16^{* * *}$ & $34.92 * * *$ \\
\hline Panellist & 11 & $35.19 * * *$ & $26.34 * * *$ & $12.29 * * *$ & $28.25 * * *$ \\
\hline Session & 1 & 0.88 & $4.68 *$ & 0.14 & 3.02 \\
\hline Replicate & 3 & $3.05 *$ & $3.96^{*}$ & 0.61 & $3.21 *$ \\
\hline $\begin{array}{l}\text { Sample Order } \\
\text { Interaction effects }\end{array}$ & 2 & 0.25 & 0.83 & 1.40 & 0.04 \\
\hline $\begin{array}{l}\text { Panellist by } \\
\text { cultivar }\end{array}$ & 55 & $1.63 *$ & $2.16^{* * *}$ & 1.25 & $2.12 * * *$ \\
\hline $\begin{array}{l}\text { Panellist by session } \\
\text { Panellist by }\end{array}$ & 11 & 1.18 & $2.29 *$ & 0.67 & 1.43 \\
\hline $\begin{array}{l}\text { replicate } \\
\text { Panellist by sample }\end{array}$ & 33 & 1.24 & 1.80 & 1.36 & $1.55^{*}$ \\
\hline order & 22 & 0.89 & 0.81 & 0.88 & 0.99 \\
\hline
\end{tabular}

$*, * *, * * *$ Significant at $\mathrm{p}<0.05,0.01$ and 0.001 , respectively. 
Table 2 Degrees of freedom (df), R-squared and F-values from analysis of variance of parameters extracted from time intensity curves for astringency in sorghum bran infusions

\begin{tabular}{|c|c|c|c|c|c|}
\hline $\begin{array}{l}\text { Source of } \\
\text { variation }\end{array}$ & df & $\begin{array}{l}\text { Time to Max } \\
\left(\mathbf{T}_{\max }\right) \\
\mathrm{R}^{2}-0.79\end{array}$ & $\begin{array}{l}\text { Intensity at Max } \\
\left(I_{\max }\right) \\
R^{2}-0.79\end{array}$ & $\begin{array}{l}\text { Total Duration } \\
\left(D_{\text {tot }}\right) \\
R^{2}-0.73\end{array}$ & $\begin{array}{l}\text { Area Under Curve } \\
\text { (AUC) } \\
\mathrm{R}^{2}-0.83\end{array}$ \\
\hline Main effects & & & & & \\
\hline Cultivar & 5 & $4.73 * * *$ & $21.89 * * *$ & $4.89 * * *$ & $22.80 * * *$ \\
\hline Panellist & 11 & $33.99 * * *$ & $19.25 * * *$ & $19.15 * * *$ & $29.95 * * *$ \\
\hline Session & 1 & 2.38 & $24.16 * * *$ & 0.01 & $20.54 * * *$ \\
\hline Replicate & 3 & $2.78 *$ & 1.94 & 1.55 & 1.61 \\
\hline $\begin{array}{l}\text { Sample Order } \\
\text { Interaction effects }\end{array}$ & 2 & 0.13 & 1.27 & 0.81 & 0.65 \\
\hline $\begin{array}{l}\text { Panellist by } \\
\text { cultivar }\end{array}$ & 55 & 1.01 & 0.99 & 0.84 & 1.15 \\
\hline $\begin{array}{l}\text { Panellist by session } \\
\text { Panellist by }\end{array}$ & 11 & 1.34 & $2.13 *$ & $2.6 * *$ & 1.81 \\
\hline $\begin{array}{l}\text { replicate } \\
\text { Panellist by sample }\end{array}$ & 33 & $1.53^{*}$ & $1.9 * *$ & 1.30 & $1.88^{* *}$ \\
\hline order & 22 & 0.66 & $1.71 *$ & 0.96 & $2.18^{* *}$ \\
\hline
\end{tabular}

$*, * *, * * *$ Significant at $\mathrm{p}<0.05,0.01$ and 0.001 , respectively. 
Table 3 Least Square Means ${ }^{1}( \pm \mathrm{SE})$ of parameters extracted from time intensity curves for bitterness and astringency $(0=$ none; $100=$ extreme $)$ of sorghum bran infusions of tannincontaining and tannin-free sorghums

\begin{tabular}{|c|c|c|c|c|c|c|c|}
\hline & \multicolumn{3}{|c|}{ Tannin sorghums } & \multicolumn{3}{|c|}{$\begin{array}{l}\text { Tannin-free } \\
\text { sorghums }\end{array}$} & \multirow[t]{2}{*}{ Means $^{2}$} \\
\hline & $\begin{array}{l}\text { PAN } \\
3860\end{array}$ & $\begin{array}{l}\text { Ex Nola } \\
97 \mathrm{GH}\end{array}$ & NS 5511 & $\begin{array}{l}\text { PAN } \\
8564\end{array}$ & Segaolane & Phofu & \\
\hline \multicolumn{8}{|l|}{ Bitterness } \\
\hline $\mathrm{T}_{\max }(\mathrm{s})$ & $27.2^{\mathrm{b}}(1.2)$ & $28.2^{\mathrm{b}}(1.2)$ & $20.9^{\mathrm{a}}(1.3)$ & $20.1^{\mathrm{a}}(1.2)$ & $18.3^{\mathrm{a}}(1.3)$ & $20.4^{\mathrm{a}}(1.3)$ & $22.5^{\mathrm{A}}$ \\
\hline$I_{\max }$ & $56.9^{\mathrm{e}}(1.9)$ & $49.1^{\mathrm{d}}(1.9)$ & $36.4^{\mathrm{bc}}(2.2)$ & $37.8^{\mathrm{c}}(1.9)$ & $31.4^{\mathrm{b}}(2.2)$ & $24.3^{\mathrm{a}}(2.1)$ & $39.3^{\mathrm{A}}$ \\
\hline $\mathrm{D}_{\text {tot }}(\mathrm{s})$ & $75.1^{\mathrm{c}}(2.7)$ & $74.1^{\mathrm{bc}}(2.7)$ & $63.3^{\mathrm{a}}(3.0)$ & $64.9^{\mathrm{ab}}(2.7)$ & $60.9^{\mathrm{a}}(3.0)$ & $59.6^{\mathrm{a}}(2.9)$ & $66.3^{\mathrm{A}}$ \\
\hline AUC & $\begin{array}{l}2673.7^{\mathrm{d}} \\
(123.5)\end{array}$ & $\begin{array}{l}2381.1^{\mathrm{d}} \\
(123.6)\end{array}$ & $\begin{array}{l}1338.6^{\mathrm{bc}} \\
(137.4)\end{array}$ & $\begin{array}{l}1512.2^{\mathrm{c}} \\
(123.6)\end{array}$ & $\begin{array}{l}1132.5^{\mathrm{ab}} \\
(137.4)\end{array}$ & $\begin{array}{l}845.9^{\mathrm{a}} \\
(133.2)\end{array}$ & $1647.3^{\mathrm{A}}$ \\
\hline \multicolumn{8}{|c|}{ Astringency } \\
\hline $\mathrm{T}_{\max }(\mathrm{s})$ & $30.8^{\mathrm{c}}(1.4)$ & $30.9^{c}(1.4)$ & $30.3^{\mathrm{c}}(1.6)$ & $25.7^{\mathrm{ab}}(1.4)$ & $26.9^{\mathrm{abc}}(1.6)$ & $23.0^{\mathrm{a}}(1.5)$ & $27.9^{\mathrm{B}}$ \\
\hline$I_{\max }$ & $55.1^{\mathrm{d}}(2.1)$ & $42.0^{\mathrm{c}}(2.1)$ & $33.9^{\mathrm{ab}}(2.3)$ & $36.6^{\mathrm{bc}}(2.1)$ & $31.4^{\mathrm{ab}}(2.3)$ & $28.9^{\mathrm{a}}(2.2)$ & $38.0^{\mathrm{A}}$ \\
\hline $\mathrm{D}_{\text {tot }}(\mathrm{s})$ & $76.2^{\mathrm{c}}(2.2)$ & $74.2^{\mathrm{c}}(2.2)$ & $72.5^{\mathrm{bc}}(2.4)$ & $67.2^{\mathrm{ab}}(2.2)$ & $65.3^{\mathrm{ab}}(2.4)$ & $64.1^{\mathrm{a}}(2.4)$ & $69.9^{\mathrm{B}}$ \\
\hline AUC & $\begin{array}{l}2639.4^{\mathrm{d}} \\
(115.5)\end{array}$ & $\begin{array}{l}1853.1^{\mathrm{c}} \\
(115.5)\end{array}$ & $\begin{array}{l}1436.7^{\mathrm{ab}} \\
(128.5)\end{array}$ & $\begin{array}{l}1562.6^{\mathrm{bc}} \\
(115.5)\end{array}$ & $\begin{array}{l}1319.1^{\mathrm{ab}} \\
(128.5)\end{array}$ & $\begin{array}{l}1102.1^{\mathrm{a}} \\
(124 .)\end{array}$ & $1632.2^{\mathrm{A}}$ \\
\hline
\end{tabular}

${ }^{1}$ Least square means of four replicate experiments and standard errors averaged across 12 panellists.

${ }^{2}$ Least square means of values for the six sorghums

${ }^{\text {abcde }}$ Least Square Means in rows with different letter notations are significantly different at $p \leq 0.05$.

${ }^{\mathrm{AB}}$ In the shaded column, least square means for bitterness and astringency pertaining to corresponding time-intensity parameters with different letter notations are significantly different at $\mathrm{p} \leq 0.05$.

$\mathrm{T}_{\max }-$ time to maximum intensity, $\mathrm{I}_{\max }-$ maximum intensity, $\mathrm{D}_{\text {tot }}-$ total duration, $\mathrm{AUC}-$ area under curve. 
Table 4 Panellists' Least Square Means ${ }^{1}$ of parameters extracted from time intensity curves for astringency and bitterness of sorghum bran infusions

\begin{tabular}{|c|c|c|c|c|c|c|c|c|}
\hline \multirow[b]{2}{*}{ Panellists } & \multirow[b]{2}{*}{$\begin{array}{l}\mathbf{T}_{\max } \\
(\mathbf{s})\end{array}$} & \multicolumn{2}{|c|}{ Bitterness } & \multirow[b]{2}{*}{$\mathbf{A U C}$} & \multirow[b]{2}{*}{$\begin{array}{l}\mathbf{T}_{\max } \\
(\mathbf{s})\end{array}$} & \multicolumn{2}{|c|}{ Astringency } & \multirow[b]{2}{*}{ AUC } \\
\hline & & $\mathbf{I}_{\max }$ & $\begin{array}{l}D_{\text {tot }} \\
\text { (s) }\end{array}$ & & & $\mathbf{I}_{\max }$ & $\begin{array}{l}D_{\text {tot }} \\
\text { (s) }\end{array}$ & \\
\hline 1 & $36.9^{\mathrm{e}}$ & $42.3^{\mathrm{de}}$ & $52.4^{\mathrm{a}}$ & $1339.7^{\mathrm{bc}}$ & $44.2^{\mathrm{d}}$ & $47.9^{\mathrm{fg}}$ & $60.9^{\mathrm{b}}$ & $1355.0^{\mathrm{ab}}$ \\
\hline 2 & $20.5^{\mathrm{c}}$ & $48.0^{\mathrm{e}}$ & $66.2^{\mathrm{cd}}$ & $1737.0^{\mathrm{cd}}$ & $24.6^{\mathrm{b}}$ & $34.0^{\mathrm{cd}}$ & $58.2^{\mathrm{b}}$ & $995.0^{\mathrm{a}}$ \\
\hline 3 & $13.8^{\mathrm{a}}$ & $18.3^{\mathrm{a}}$ & $64.4^{\mathrm{bcd}}$ & $578.5^{\mathrm{a}}$ & $20.0^{\mathrm{ab}}$ & $30.6^{\mathrm{bcd}}$ & $66.2^{\mathrm{b}}$ & $1223.0^{\mathrm{a}}$ \\
\hline 4 & $14.3^{\mathrm{ab}}$ & $64.3^{\mathrm{f}}$ & $72.8^{\mathrm{de}}$ & $3243.1^{\mathrm{e}}$ & $20.1^{\mathrm{ab}}$ & $67.7^{\mathrm{h}}$ & $82.5^{\mathrm{c}}$ & $3899.0^{\mathrm{e}}$ \\
\hline 5 & $14.7^{\mathrm{ab}}$ & $32.3^{\mathrm{bc}}$ & $56.9^{\mathrm{abc}}$ & $1082.0^{\mathrm{b}}$ & $16.7^{\mathrm{a}}$ & $43.4^{\mathrm{efg}}$ & $64.0^{\mathrm{b}}$ & $1813.4^{\mathrm{c}}$ \\
\hline 6 & $25.3^{d}$ & $39.5^{\mathrm{cd}}$ & $82.9^{\mathrm{e}}$ & $1905.6^{\mathrm{d}}$ & $20.7^{\mathrm{ab}}$ & $34.3^{\mathrm{de}}$ & $87.6^{\mathrm{c}}$ & $1707.5^{\mathrm{bc}}$ \\
\hline 7 & $23.0^{\mathrm{cd}}$ & $31.3^{\mathrm{b}}$ & $53.9^{\mathrm{ab}}$ & $1036.6^{\mathrm{ab}}$ & $27.2^{\mathrm{b}}$ & $24.8^{\mathrm{ab}}$ & $62.7^{\mathrm{b}}$ & $969.2^{\mathrm{a}}$ \\
\hline 8 & $17.6^{\mathrm{abc}}$ & $32.0^{\mathrm{bc}}$ & $60.3^{\mathrm{abc}}$ & $1260.4^{b c}$ & $16.0^{\mathrm{a}}$ & $26.1^{\mathrm{abc}}$ & $66.3^{\mathrm{b}}$ & $1072.5^{\mathrm{a}}$ \\
\hline 9 & $15.7^{\mathrm{ab}}$ & $27.1^{\mathrm{b}}$ & $85.5^{\mathrm{e}}$ & $1285.3^{b c}$ & $32.3^{c}$ & $23.1^{\mathrm{a}}$ & $88.0^{\mathrm{c}}$ & $1375.8^{\mathrm{abc}}$ \\
\hline 10 & $22.6^{\mathrm{cd}}$ & $28.7^{\mathrm{b}}$ & $55.1^{\mathrm{ab}}$ & $1248.3^{b}$ & $46.8^{d}$ & $35.6^{\mathrm{de}}$ & $65.1^{\mathrm{b}}$ & $1390.5^{\mathrm{ac}}$ \\
\hline 11 & $46.7^{\mathrm{f}}$ & $61.0^{\mathrm{f}}$ & $89.4^{\mathrm{e}}$ & $3686.5^{\mathrm{e}}$ & $46.4^{\mathrm{d}}$ & $48.0^{\mathrm{g}}$ & $89.0^{\mathrm{c}}$ & $2897.9^{d}$ \\
\hline 12 & $18.9^{\mathrm{bc}}$ & $47.2^{\mathrm{e}}$ & $56.1^{\mathrm{abc}}$ & $1365.1^{\mathrm{bc}}$ & $20.2^{\mathrm{ab}}$ & $40.0^{\text {def }}$ & $48.3^{\mathrm{a}}$ & $1127.3^{\mathrm{a}}$ \\
\hline
\end{tabular}

${ }^{1}$ Least Square Means of four replicate experiments.

${ }^{\text {abcde }}$ Least Square Means in columns with different letter notations are significantly different at $\mathrm{p} \leq 0.01$. $\mathrm{T}_{\max }$ - time to maximum intensity, $\mathrm{I}_{\max }-$ maximum intensity, $\mathrm{D}_{\text {tot }}-$ total duration, $\mathrm{AUC}$ - area under curve. 